\title{
Permanent neonatal diabetes by a new mutation in KCNJ1 1: unsuccessful switch to sulfonylurea
}

Eva Lau', Cintia Correia², Paula Freitas', Claúdia Nogueira ${ }^{3}$, Maria Costa $^{3}$, Ana Saavedra ${ }^{3}$, Carla Costa ${ }^{2}$, Davide Carvalho', Manuel Fontoura ${ }^{2}$

\section{SUMMARY}

Permanent neonatal diabetes (PNDM) can result from activating heterozygous mutations in KCNJ11 gene, encoding the Kir6.2 subunit of the pancreatic ATP-sensitive potassium channels $\left(\mathrm{K}_{\mathrm{ATP}}\right)$. Sulfonylureas promote $\mathrm{K}_{\mathrm{ATP}}$ closure and stimulate insulin secretion, being an alternative therapy in PNDM instead of insulin. Male, 20 years old, diagnosed with diabetes at 3 months of age. The genetic study identified a novel heterozygous mutation in exon 1 of the KCNJ11 gene - KCNJ11:c1001G>7 (p.Gly334Val) - and confirmed the diagnosis of PNDM. Therefore it was attempted to switch from insulin therapy to sulfonylurea. During glibenclamide institution C-peptide levels increased, however the suboptimal glycemic control lead us to restart an intensive insulin scheme. This new variant of KCNJ11 mutation had a phenotypic lack of response to sulfonylurea therapy. Age, prior poor metabolic control and functional change of $\mathrm{K}_{\text {ATP }}$ channel induced by this specific mutation may explain the observed unsuccessful switch to sulfonylurea. Interestingly, C-peptide levels raise during glibenclamide administration support some degree of improvement in insulin secretory capacity induced by the treatment. Understanding the response to sulfonylurea is crucial as successful treatment may be life-changing in these patients. Arch Endocrinol Metab. 2015;59(6):559-61
'Departamento de Endocrinologia, Diabetes e Metabolismo, Centro Hospitalar São João; Faculdade de Medicina da Universidade do Porto; Instituto de Investigação e Inovação em Saúde, Universidade do Porto, Porto, Portugal ${ }^{2}$ Unidade de Endocrinologia Pediátrica e Diabetologia, Departamento de Pediatria, Centro Hospitalar São João; Faculdade de Medicina da Universidade do Porto, Porto, Portugal ${ }^{3}$ Departamento de Endocrinologia, Diabetes e Metabolismo, Centro Hospitalar São João; Faculdade de Medicina da Universidade do Porto, Porto, Portugal

Correspondence to:

Eva Lau

Departamento de Endocrinologia,

Diabetes e Metabolismo, Centro Hospitalar

São João, Faculdade de Medicina da

Universidade do Porto, Instituto de

Investigação e Inovação em Saúde,

Universidade do Porto

Alameda Professor Hernâni Monteiro

4200-319 - Porto, Portugal

evalau.med@gmail.com

Received on Apr/11/2015

Accepted on May/27/2015

DOI: 10.1590/2359-3997000000076

\section{INTRODUCTION}

$\mathrm{P}$ ermanent neonatal diabetes mellitus (PNDM) is a rare form of diabetes with an estimated prevalence at 1 in 252000 (1). It is characterized by the onset of diabetes before the age of 6 months, being a permanent condition that does not goes into remission. This form of diabetes can be caused by variants of several genes, including KCNJl 1, ABCC8, GCK, and IPFl gene (2). Approximately half of the cases are caused by a mutation in KCNJ11, which encodes the Kir6.2 subunit of the pancreatic ATP-sensitive potassium channels $\left(\mathrm{K}_{\mathrm{ATP}}\right)(3)$; the majority of these patients develop isolated PNDM, but $20 \%$ have associated neurologic disturbances like DEND syndrome, characterized by developmental delay, epilepsy, and neonatal diabetes (3).

$\mathrm{K}_{\text {ATP }}$ channel is a key regulator of beta-cell insulin secretion. In the pancreatic beta cell, the intracellular increase of ATP, due to glucose metabolism, leads to $\mathrm{K}_{\mathrm{ATP}}$ channels closure, which causes membrane depolarization and opening of voltage-gated $\mathrm{Ca}^{2+}$ channels; this $\mathrm{Ca}^{2+}$ influx can trigger insulin release (4).
Activating KCNJll mutations are associated with diabetes: these mutations cause an inappropriate activation of $\mathrm{K}_{\mathrm{ATP}}$ channel channels, which fail to close in response to an increase in plasma glucose levels, leading to insulin secretion dysfunction $(5,6)$. The identification of Kir6.2 (KCNJ11) mutations has critical therapeutic implications, since sulfonylureas, a class of oral anti-diabetic agents, act through that channels (7). Sulfonylureas are able to promote $\mathrm{K}_{\mathrm{ATP}}$ channels closure by an ATP-independent route, thereby stimulating insulin secretion in those patients (8). Thus, sulfonylureas may represent a suitable therapy for patients with KCNJll mutations, instead of insulin therapy.

\section{CASE REPORT}

A caucasian male, son of non-consanguineous healthy parents, was born by a dystocic parturition (forceps) at 36 weeks of gestation. Prenatal history was remarkable for intrauterine growth restriction. The birth weight was $1800 \mathrm{~g}\left(<3^{\text {rd }}\right.$ centile $)$, length $44 \mathrm{~cm}\left(10^{\text {th }}\right.$ centi- 
le) and head circumference $33 \mathrm{~cm}\left(50^{\text {th }}\right.$ centile $)$. At 3 months old he was diagnosed with a febrile acute otitis media and was medicated with amoxicillin. During this acute process he became dehydrated and was admitted to hospital. Laboratory workup revealed persistent hyperglycemia and the diagnosis of diabetes was made.

At diabetes onset, laboratory study showed negative anti-insulin and anti-GAD autoantibodies. He was started with an intensive insulin treatment (> 0.5 unit/ $\mathrm{kg}$ /day) in a basal-bolus insulin regimen but he always had a poor glycemic control (HbAlc 8-12.5\%). During his childhood, there was no developmental delay, learning difficulties or history of epilepsy. At 20 years old it was carried out a genetic study for KCNJll gene. Sequencing of the entire coding region identified a heterozygous KCNJl1:cl001G>7 (p.Gly334Val) in exon 1 of the KCNJll gene, a novel variant, confirming the diagnose of PNDM. He was thereby admitted in our department to attempt for insulin switch to sulfonylurea, according to a standardized protocol (9). Prior to treatment transition, the patient was taking 40 units of glargin insulin at breakfeast time, and 4 units of fastacting insulin (insulin aspart) four times daily, before meals, adjusted according to capillary glucose levels. His body mass index (BMI) was $24.3 \mathrm{~kg} / \mathrm{m}^{2}$ (weight: $74 \mathrm{~kg}$, height: $1.75 \mathrm{~m})$. Glibenclamide was started at a dose of $0.1 \mathrm{mg} / \mathrm{kg} /$ day $(7.5 \mathrm{mg}$ twice daily), with daily increments of $0.2 \mathrm{mg} / \mathrm{kg} /$ day, reaching $1.6 \mathrm{mg} / \mathrm{kg} /$ day ( $60 \mathrm{mg}$ bid). Insulin glargine was gradually tapered and suspended after 5 days. During glibenclamide treatment, glucose levels were always rapidly interchangeable between hypoglycemia and hyperglycemia (> 200 $\mathrm{mg} / \mathrm{dL}$ ). This metabolic instability has made impossible to discharge aspartic insulin. C-peptide levels increased from $0.08 \mathrm{ng} / \mathrm{mL}$ to $1.03 \mathrm{ng} / \mathrm{mL}$ (normal range: 1.1 4.4) after starting glibenclamide. However, given the suboptimal glycemic control and according to patient's preference, it was decided to suspend the sulfonylurea treatment and restart an intensive insulin scheme.

\section{DISCUSSION}

Permanent forms of diabetes presented before 6 months raise the clinical suspicion of PNDM. The identification of the genetic etiology in this form of diabetes has important clinical implications, since sulfonylureas may be an effective and alternative treatment, instead of insulin therapy $(8,10)$. In the past, patients with neonatal diabetes were treated with insulin therapy as they were usually classified as having an early-onset form of type 1 diabetes. The identification of gain-of-function mutations in $\mathrm{K}_{\text {ATP }}$ channel genes has raised the possibility of these patients being treated with an oral agent. Sulfonylureas may have double benefits in PNDM, comparing to insulin therapy: promotion of a global improvement in glycemic control, causing reduction in blood glucose fluctuations; and, consequently, risk reduction of diabetic complications and improvement of quality of life of the affected patients $(11,12)$.

Although sulfonylureas seem highly effective and safe in the treatment of the majority of patients, not all respond. This case represents an unsuccessful example of transition from insulin therapy to sulfonylurea. Therefore it is important to reflect about the possible associated reasons, which may justify the unsuccessful switch. Firstly, the attempt to withdrawal insulin treatment began at an adult age and after a long period of poor glycemic control (HbAlc 8-12.5\%). Age and poor metabolic control seem to be important predictors of sulfonylureas responsiveness, since an effective transfer is less likely in older patients, with worse glycemic control $(13,14)$. In addition, starting sulfonylureas treatment at later age is associated with increased dose requirement. Although the roles of age and glucose homeostasis are not completely understood, some elegant studies in mouse models might further expand our knowledge: mice with uncontrolled diabetes had less functioning beta cells, comparing to those treated with insulin therapy, whose beta cells were preserved (15). So, poor long-term glucose control, enhanced in older patients, may result in decline and impairment of beta cells function, which may further explain the lack of response to sulfonylureas.

Secondly, the functional properties of $\mathrm{K}_{\mathrm{ATP}}$ channel predict the clinical response to sulfonylurea therapy observed in these patients (8). It was shown that tolbutamide treatment blocked more than 75 percent of the $\mathrm{K}_{\text {ATP }}$ channel in patients carrying KCNJ11 mutations that had clinical response to sulfonylureas. In contrast, patients who failed to respond had less than 65 percent blockage with tolbutamide (8). Thus, the channel changes induced by this specific novel variant of KCNJl1 gene, a mutation on cl001G>7 (p.Gly334Val), may also explain the observed reduction in drug sensitivity. However, it is important to notice the rise in C-peptide levels during glibenclamide administration, which may reflect a partial improvement in the insulin secretory capacity induced by the treatment. Thus, we might 
speculate that the changes on $\mathrm{K}_{\text {ATP }}$ channel induced by this novel variant on KCNJll might not be irreversible and may respond to sulfonylureas, mainly if the attempt to switch from insulin can be achieved early in life and the patient has prior good glycemic control.

We report, for the first time, the heterozygous mutation KCNJ11:cl001G>7 (p.Gly334Val) in exon 1 of the KCNJll gene, in a patient with permanent neonatal diabetes mellitus. This case highlights the clinicians to consider a neonatal form of diabetes if diagnosis is made up within six months of life. The identification of this form of diabetes may be life-changing, mainly if sulfonylurea treatment could be well-succeed in early life.

Disclosure: no potential conflict of interest relevant to this article was reported.

\section{REFERENCES}

1. Kanakatti Shankar R, Pihoker C, Dolan LM, Standiford D, Badaru A, Dabelea D, et al.; SEARCH for Diabetes in Youth Study Group. Permanent neonatal diabetes mellitus: prevalence and genetic diagnosis in the SEARCH for Diabetes in Youth Study. Pediatr Diabetes. 2013;14(3):174-80.

2. Polak $M$, Cavé $H$. Neonatal diabetes mellitus: a disease linked to multiple mechanisms. Orphanet J Rare Dis. 2007;2(1):12.

3. Hattersley AT, Ashcroft FM. Activating mutations in Kir6.2 and neonatal diabetes: new clinical syndromes, new scientific insights, and new therapy. Diabetes. 2005;54(9):2503-13.

4. Ashcroft FM. K(ATP) channels and insulin secretion: a key role in health and disease. Biochem Soc Trans. 2006;34(Pt 2):243-6.

5. Gloyn AL, Reimann F, Girard C, Edghill EL, Proks P, Pearson ER, et al. Relapsing diabetes can result from moderately activating mutations in KCNJ11. Hum Mol Genet. 2005;14(7):925-34.
6. Proks P, Antcliff JF, Lippiat J, Gloyn AL, Hattersley AT, Ashcroft FM. Molecular basis of Kir6.2 mutations associated with neonatal diabetes or neonatal diabetes plus neurological features. Proc Natl Acad Sci U S A. 2004;101(50):17539-44.

7. Ashcroft FM. New uses for old drugs: neonatal diabetes and sulphonylureas. Cell Metab. 2010;11(3):179-81.

8. Pearson ER, Flechtner I, Njølstad PR, Malecki MT, Flanagan SE, Larkin $B$, et al. Switching from insulin to oral sulfonylureas in patients with diabetes due to Kir6.2 mutations. N Engl J Med. 2006;355(5):467-77.

9. Hattersley A, Pearson E. Transferring patients with diabetes due to a KIR6.2 mutation from insulin to sulphonylureas. Providing information for patients and professionals on research and clinical care in genetic types of diabetes. [Internet]. [cited 2014 Dec 5]. Available from: <http://www.diabetesgenes.org/content/transferringpatients-diabetes-due-kir62-mutation-insulin-sulphonylureas>.

10. Thewjitcharoen $Y$, Wanothayaroj $E$, Himathongkam $T$, Flanagan SE, Ellard S, Hattersley AT. Permanent neonatal diabetes misdiagnosed as type 1 diabetes in a 28-year-old female: a life-changing diagnosis. Diabetes Res Clin Pract. 2014;106(2):e22-4.

11. Sagen JV, Raeder H, Hathout E, Shehadeh N, Gudmundsson K, Baevre $\mathrm{H}$, et al. Permanent neonatal diabetes due to mutations in KCNJ11 encoding Kir6.2: patient characteristics and initial response to sulfonylurea therapy. Diabetes. 2004;53(10):2713-8.

12. Zung A, Glaser B, Nimri R, Zadik Z. Glibenclamide treatment in permanent neonatal diabetes mellitus due to an activating mutation in Kir6.2. J Clin Endocrinol Metab. 2004;89(11):5504-7.

13. Støy J, Greeley SA, Paz VP, Ye H, Pastore AN, Skowron KB, et al.; United States Neonatal Diabetes Working Group. Diagnosis and treatment of neonatal diabetes: a United States experience. Pediatr Diabetes. 2008;9(5):450-9.

14. Wambach JA, Marshall BA, Koster JC, White NH, Nichols CG. Successful sulfonylurea treatment of an insulin-naïve neonate with diabetes mellitus due to a KCNJ11 mutation. Pediatr Diabetes. 2010;11(4):286-8.

15. Remedi MS, Kurata HT, Scott A, Wunderlich FT, Rother E, Kleinridders $A$, et al. Secondary consequences of beta cell inexcitability: identification and prevention in a murine model of K(ATP)-induced neonatal diabetes mellitus. Cell Metab. 2009;9(2):140-51. 